\title{
Secretion of glucagon-like peptide-1 (GLP-1) in type 2 diabetes: what is up, what is down?
}

\author{
M. A. Nauck • I. Vardarli • C. F. Deacon • J. J. Holst • \\ J. J. Meier
}

Received: 3 April 2010 /Accepted: 30 July 2010/Published online: 25 September 2010

(C) Springer-Verlag 2010

\begin{abstract}
The incretin hormones gastric inhibitory polypeptide and especially glucagon-like peptide (GLP) have an important physiological function in augmenting postprandial insulin secretion. Since GLP-1 may play a role in the pathophysiology and treatment of type 2 diabetes, assessment of meal-related GLP-1 secretory responses in type 2 diabetic patients vs healthy individuals is of great interest. A common view states that GLP-1 secretion in patients with type 2 diabetes is deficient and that this applies to a lesser degree in individuals with impaired glucose tolerance. Such a deficiency is the rationale for replacing endogenous incretins with GLP-1 receptor agonists or re-normalising active GLP-1 concentrations with dipeptidyl peptidase-4 inhibitors. This review summarises the literature on this topic, including a meta-analysis of published studies on GLP-1 secretion in individuals with and without diabetes after oral glucose and mixed meals. Our analysis does not support the contention of a generalised defect in nutrient-related GLP-1 secretory responses in type 2 diabetes patients. Rather, factors are identified that may determine individual incretin secretory responses and explain some of
\end{abstract}

M. A. Nauck $(\bowtie) \cdot$ I. Vardarli

Diabeteszentrum Bad Lauterberg,

Kirchberg 21,

37431 Bad Lauterberg im Harz, Germany

e-mail: M.Nauck@diabeteszentrum.de

C. F. Deacon · J. J. Holst

Department of Medical Physiology, Panum Institute,

University of Copenhagen,

Copenhagen, Denmark

\section{J. J. Meier}

Medizinische Klinik I, St Josef-Hospital Bochum,

Ruhr-University Bochum,

Bochum, Germany the variations in published findings of group differences in GLP-1 responses to nutrient intake.

Keywords Glucagon-like peptide-1 - Gut hormones . Incretin hormones $\cdot$ L-cell $\cdot$ Meta-analysis .

Pathophysiology $\cdot$ Review
Abbreviations
DPP Dipeptidyl peptidase
GIP Gastric inhibitory polypeptide
GLP Glucagon-like peptide
GPR G-protein-coupled receptor

\section{Introduction}

Incretins are gut-derived hormones that can stimulate insulin secretion and make a significant contribution to overall postprandial insulin release [1-3]. One of them, glucagonlike peptide (GLP)-1, has glucose-lowering properties [4, 5] and has been the basis of two novel classes of glucoselowering agents, incretin mimetics (i.e. GLP-1 receptor agonists) and inhibitors of protease dipeptidyl peptidase (DPP)-4 (incretin enhancers) [3, 6-8]. Since the latter are thought to exert their glucose-lowering activity by preventing the degradation and inactivation (with regard to insulinotropic effects) of endogenously released intact, biologically active GLP-1 [9], their pharmacological action should critically depend on availability of the major substrate, GLP-1. Against this background, reports that GLP-1 secretion from L-cells is reduced in patients with type 2 diabetes $[10,11]$ have prompted several hypotheses about how this affects the estimated clinical effectiveness of these novel drugs. They have mainly been based on a study by Toft-Nielsen et al. [12], which reported an increase in 
'total' GLP-1 (all forms including intact GLP-1 [7-36 amide] and the DPP-4-degraded, non-insulinotropic form GLP-1 [9-36 amide]) from basal levels of around $5 \mathrm{pmol} / 1$ to mean values of about 16 to $17 \mathrm{pmol} / 1$ in 33 healthy participants and 13 to $14 \mathrm{pmol} / 1$ in 54 type 2 diabetic patients, both after $60 \mathrm{~min}$. In the second hour, peak GLP1 concentrations were maintained in healthy participants, but returned to lower levels in type 2 diabetic patients. Overall, this resulted in a 53\% reduction in integrated incremental GLP-1 concentrations (AUC above baseline) in type 2 diabetic patients relative to healthy controls and a $19 \%$ reduction in the total AUC (above 0 pmol/l). These differences were highly significant. Participants with impaired oral glucose tolerance ranked between healthy volunteers and type 2 diabetic patients and thus had an intermediate GLP-1 response. Based on this largest available cross-sectional study comparing GLP-1 release in type 2 diabetic patients and healthy controls, it has specifically been pointed out that:

1. Slightly reduced GLP-1 concentrations after a meal in participants with impaired oral glucose tolerance and more severely impaired GLP-1 secretion in type 2 diabetic patients, as demonstrated in cross-sectional analyses, may translate into a progressive loss of the ability to secrete GLP-1 with advancing type 2 diabetes as part of the process of disease progression.

2. This loss of GLP-1 secretion is part of the pathophysiological explanation for a lost incretin effect [13, 14], a phenomenon typically observed in patients with type 2 diabetes.

3. The above point (2) provides evidence that loss of GLP-1 secretion with immediate pathophysiological consequences (reduced incretin effect as part of impaired postprandial beta cell function) calls for a replacement therapy with incretin-based glucose-lowering medications [3].

4. Based on such reasoning, DPP-4 inhibitors cannot be expected $[7,8]$ to lower blood glucose in later stages of type 2 diabetes (because of lost ability to secrete GLP-1).

This review aims to put these hypotheses into perspective with the available data on GLP-1 release in healthy and type 2 diabetic participants, and to address common differences of opinion and some potential misconceptions in the interpretation of commonly quoted landmark publications.

\section{Mechanisms of L-cell GLP-1 secretion}

Physiologically, L-cells, which are most common in the distal parts of the intestines [15], are stimulated to secrete all their secretory products (GLP-1, GLP-2, gut-derived glucagon [also called glicentin], peptide tyrosine tyrosine, oxyntomodulin) in response to nutrient ingestion $[16,17]$.
The main meal components that act as potent stimulants of GLP-1 secretion are glucose [18] and triacylglycerol [19], but fructose and some proteins are also effective. Oral glucose is a good stimulus for the release of GLP-1, whereas plasma GLP-1 concentrations do not change when glucose is administered intravenously, i.e. by bypassing absorptive processes in the gut $[13,20]$. Typically, 'total' GLP-1 concentrations are between 5 and $15 \mathrm{pmol} / 1$ in the basal state, rising to between 20 and $60 \mathrm{pmol} / 1$ after oral glucose or meals [12, 16, 21].

The temporal pattern of nutrient intake-related increments in plasma GLP-1 begins with a rather early rise (starting approximately 10 to $15 \mathrm{~min}$ after eating [22]), peaks during the second hour and then slowly declines to baseline over several hours. Some studies suggest a biphasic pattern, with an early peak followed by a nadir and a second rise in GLP-1 concentrations [23], but other studies in humans tend to describe monophasic secretory responses [12, 24, 25].

The intracellular events leading to L-cell secretion have been reviewed in detail [26]. Novel components of L-cells that are involved in nutrient sensing are sweet taste receptors and the G-protein gustducin [27], as well as NEFA receptors or their modifications such as G-proteincoupled receptor (GPR) 119 [28], GPR 120 [29] and perhaps GPR 40 [30]. GPR 119 and 120 are rather specific for long-chain monounsaturated NEFA such as $\alpha$-linolenic acid. It is not known whether GPR 119 and/or 120 are located to the luminal (brush border) membrane, which is primarily involved in sensing NEFA in chymus, or to the baso-lateral membrane, where they would be exposed to interstitial fluid more similar in composition to plasma (Fig. 1).

\section{Where in the gut is GLP-1 released?}

Especially the predominant location of L-cells in the distal parts of the gut [15] has prompted hypotheses about the early increase in GLP-1 concentrations immediately after starting a meal $[12,16,20,21]$. It has been difficult to understand how L-cells in the distal ileum can be exposed to nutrients minutes after their ingestion [31]. Measurement of plasma concentration profiles after nutrient ingestion (e.g. Fig. 2, with the early phase being the consequence of potential indirect mechanisms, followed by a later phase of direct stimulation, when gut contents have travelled to distal parts of the intestines) have not accumulated much evidence in favour of a biphasic GLP-1 response in human participants. Nevertheless, some indirect mechanisms have been proposed. These potential pathways include 'uppergut signals', i.e. stimulation of the autonomous nervous system [32-35], as well as endocrine transmission through gastrointestinal hormones [33, 36, 37], both of which may 
Fig. 1 The L-cell with components that may be involved in triggering or modulating GLP-1 secretion. The primary process leading to release of preformed secretory granules may start with the absorption of glucose through glucose transporters in microvilli of the luminal (brush border) membrane. Additional signals are sweet taste receptors, receptors for NEFA, neurotransmitters (acetylcholine, gastrin-releasing peptide, others), gastrointestinal hormones (GIP) and glucagon. For details, see text. Glc, glucose

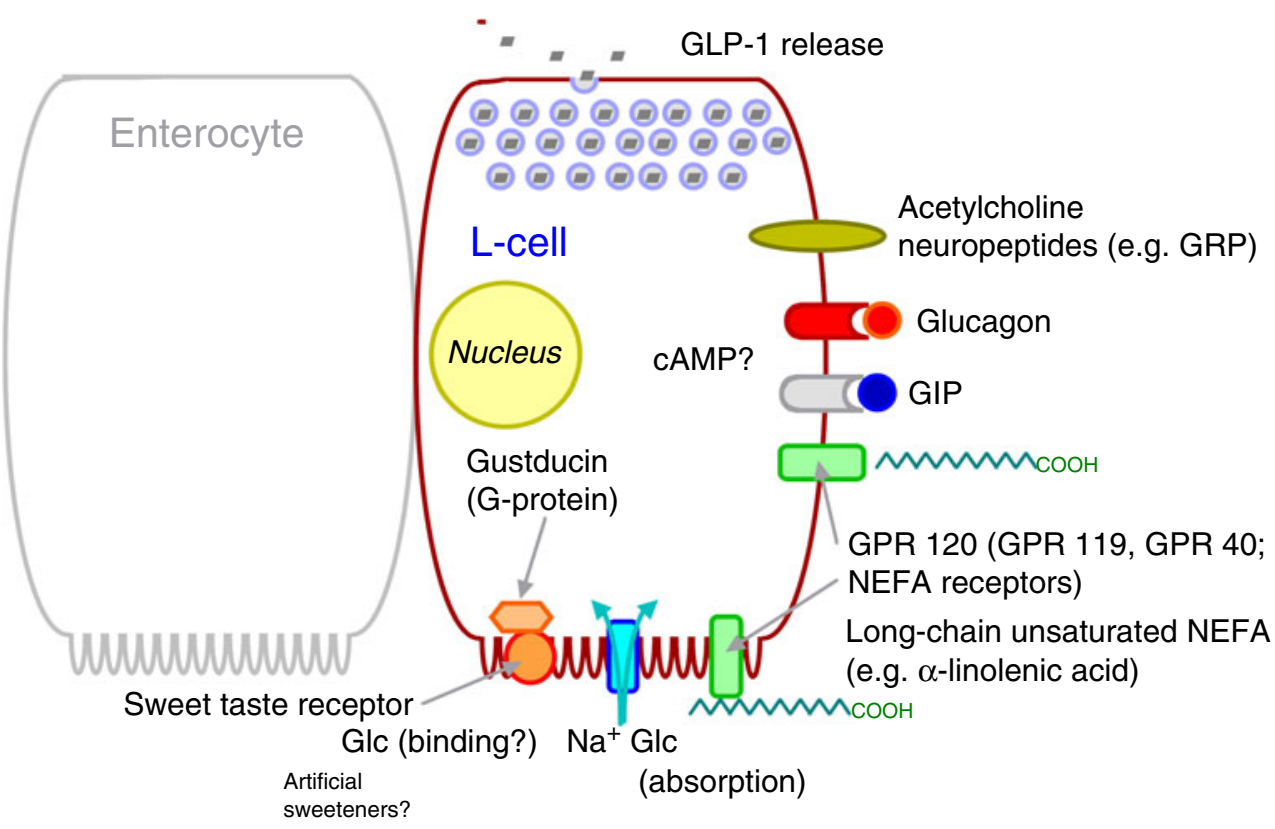

a rise in GLP-1 concentrations in human participants with [38] and without [38, 39] type 2 diabetes. Neurotransmitters such as acetylcholine [32, 34, 40] and gastrin-releasing peptide [37] also trigger GLP-1 release, suggesting the intramural enteric nervous system is involved in mediating the be activated when appropriate nutrients enter the duodenum or upper jejunum. Along these lines, gastric inhibitory polypeptide (GIP) triggers release of GLP-1 from cell lines resembling L-cells and in animal experiments (rodents) [36]. However, even high doses of exogenous GIP do not lead to b

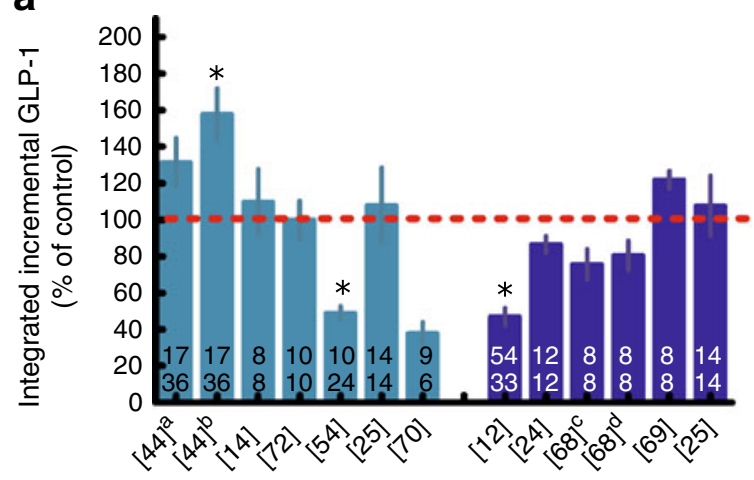

Studies [reference number]

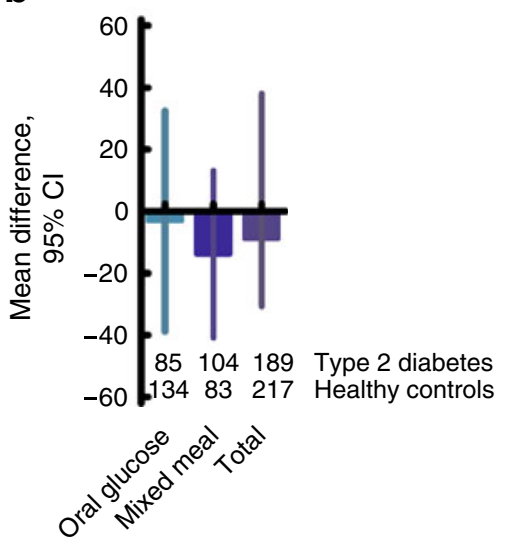

Fig. 2 Integrated responses of 'total' GLP to oral glucose or mixed meals based on individual studies (a) reporting integrated incremental 'total' GLP-1 responses in patients with type 2 diabetes and an appropriate control group (weight-matched, non-diabetic participants) and using non-specific assays that measured intact and DPP-4-degraded forms of GLP-1. The response in type 2 diabetic patients (mean \pm SEM) is expressed as percentage of the mean value in the control group. ${ }^{*} p<0.05$ vs control. Numbers in bars indicate number of type 2 diabetic patients (upper row) and control participants (lower row) studied. Studies are indicated by reference number, i.e. $[12,14,24,25,44,54$, 68-70, 72]. ${ }^{\mathrm{a}} 0-20 \mathrm{~min},{ }^{\mathrm{b}} 20-120 \mathrm{~min},{ }^{\mathrm{c}} 0-30 \mathrm{~min},{ }^{\mathrm{d}} 30-180 \mathrm{~min}$. b For the meta-analysis, electronic databases (PubMed and EMBASE) were searched (until 28 February 2010) for studies dealing with the secretion and providing integrated incremental responses of GLP-1 in healthy participants and patients with type 2 diabetes after an oral glucose tolerance test $(75 \mathrm{~g})$ and/or after a standardised mixed meal. Two independent authors (M. Nauck and I. Vardarli) examined the studies and extracted data. We included nine studies with 13 datasets and 406 participants (189 patients with type 2 diabetes, 217 healthy controls) in the meta-analysis. Data from studies using early, non-specific assays that would cross-react with the major proglucagon fragment $[18,38,71]$ were excluded. As effect size, we used the mean difference. Pooled estimates were obtained using the DerSimonian and Laird random effects model. The pooled estimates of the mean difference of integrated incremental plasma concentrations of GLP-1 between patients with type 2 diabetes and healthy controls are shown. After an oral glucose challenge as well as after a mixed meal test, the integrated incremental plasma concentrations of GLP-1 were not significantly different between patients with type 2 diabetes and controls $(p=0.44)$. Light blue, oral glucose; dark blue, mixed meal 
'upper gut signal'. In a recent study, GLP-1 release triggered by oleate was attenuated by a cholecystokinin type 1 receptor antagonist [41].

However, gut resections at any level of the small or large intestines do not typically lead to reduced GLP-1 secretion [42]. This may indicate that the release of GLP-1 occurs primarily from L-cells immediately exposed to ingested nutrients (i.e. L-cells in the upper parts of the small intestine), rather than from those parts of the gut where the majority of L-cells are located (i.e. the ileum and large intestine) [43].

In fact, L-cells have also been identified in the duodenum [44] and certainly in the jejunum [15], with the respective numbers increasing aborally towards the ileum and colon/ rectum [45]. It has been estimated that the amount of GLP-1 secreted after ingestion of a single nutrient load (calculated as integrated incremental response multiplied by the known metabolic clearance rate for GLP-1) accounts for about $10 \%$ of the GLP-1 content of jejunal L-cells [46]. A second argument in favour of direct stimulation of upper-gut L-cells is the observation that the release of GIP is closely related to that of GLP-1, even at an intra-individual level, indicating that some individuals have a poor response of GIP and GLP-1, and others have average or higher release of both incretin hormones [20]. Consistent with this observation, a subset of entero-endocrine cells has been shown to coexpress GIP and the proglucagon gene, suggesting concomitant secretion of both incretin hormones from such cells [45].

Further evidence for immediate secretion of GLP-1 from L-cells in the proximal gut comes from work by Schirra et al. [47], in which GIP and GLP-1 secretion was determined in relation to the gastro-duodenal transit of nutrients. These studies revealed a rapid onset of GIP and GLP-1 secretion after ingestion of oral glucose, along with high rates of nutrients passing into the duodenum. Interestingly, the nutrient flow rates required to sustain stimulated secretion of incretin hormones were far higher for GLP-1 $(6 \mathrm{~kJ} / \mathrm{min})$ than for GIP $(<1 \mathrm{~kJ} / \mathrm{min})$ [48]. This suggests that the velocity of transpyloric gastric content movement required to stimulate K-cells in the duodenum is lower than that required to stimulate L-cells at a more distal location (i.e. at least the proximal jejunum or further down), where significant numbers of L-cells can be found [15]. On the basis of the evidence available, we hypothesise that direct stimulation of the more proximal L-cells is the predominant mechanism. However, the relative contributions of direct and indirect mechanisms prompting secretion of GLP-1 in humans remain to be fully elucidated.

\section{GLP-1 secretion in patients with type 2 diabetes}

GLP-1 hypersecretion was described in some early studies $[18,49]$ in response to the ingestion of oral glucose, probably related to the use of side-viewing antibodies, which also detect the major proglucagon fragment [50]. More recent studies have described either no abnormalities at all in oral glucose-induced GLP-1 secretion or GLP-1 hyposecretion (Fig. 2). Meal-induced GLP-1 responses were significantly reduced in the above-mentioned largest cross-sectional study [12] by Toft-Nielsen et al. and more similar to those found in healthy participants in some other, smaller studies (Fig. 2). The second-largest recent study, by Vollmer et al. [25], found no impairment in mixed mealinduced GLP-1 secretion. The bottom line suggests that there is some variation in GLP-1 secretion and that in some cohorts, on balance, the GLP-1 response is somewhat reduced, whereas in other studies such differences are not as apparent (Fig. 2).

Since in some of the studies analysed type 2 diabetic patients were treated with metformin, which has been shown to enhance GLP-1 responses [51], any potential difference in GLP-1 secretory responses between type 2 diabetic patients and healthy participants may have been modified by this mechanism.

In the absence of a more general difference in GLP-1 secretory responses between type 2 diabetic patients and healthy participants, we have attempted to identify participant/ patient characteristics that would determine individual GLP-1 responses: Fig. 3 shows univariate regression analysis for GLP-1 secretory responses after oral glucose ingestion, from which responses appear to be predicted by baseline characteristics such as age, body weight (obesity), fasting NEFA concentrations and fasting glucagon concentrations. Similar relationships can be found for mixed meal-induced GLP-1 secretory responses and for GIP secretion (details not shown) in relation to baseline characteristics. As shown in Table 1, most of the individual factors found to be significantly related to GLP-1 secretory responses in univariate analyses remained significant in a multivariate analysis, with similar results for GLP-1 responses induced by oral glucose or mixed meal ingestion. Some relationship between obesity and GLP-1 secretion has been noted before $[12,52]$. Exogenous glucagon has been found to be associated with suppressed GLP-1 secretion [25], although in the isolated, perfused gut no such interaction was apparent [53]. The fact that variables related to obesity no longer showed a strongly significant correlation in the multivariate analysis (Table 1) may be related to the influence of associated factors, e.g. elevated NEFA concentrations. Certainly, hyperglycaemia (or oral glucose tolerance) did not turn out to be a strong predictor of GLP-1 secretion, suggesting that other characteristics of type 2 diabetic patients not represented by elevated glucose concentrations in the fasting or postprandial state may determine GLP-1 secretion, although opinions differ [54]; insulin resistance, moreover, has also been described as a factor impairing GLP-1 release [23]. 
Fig. 3 Univariate correlation of BMI (a), age (b), fasting glucagon (c) and NEFA (d) to integrated incremental responses of GLP-1 following ingestion of a mixed meal in participants with normal oral glucose tolerance (green symbols, $n=14$ ), impaired oral glucose tolerance (blue symbols, $n=17$ ) and type 2 diabetes (red symbols, $n=17)$. Data were re-analysed from Vollmer et al. [25]. a $r^{2}=0.037, p=0.19$; b $r^{2}=0.066, p=0.079 ; \mathbf{c} r^{2}=$ $0.142, p=0.0082 ; \mathbf{d} r^{2}=0.081$, $p=0.049$

\section{a}
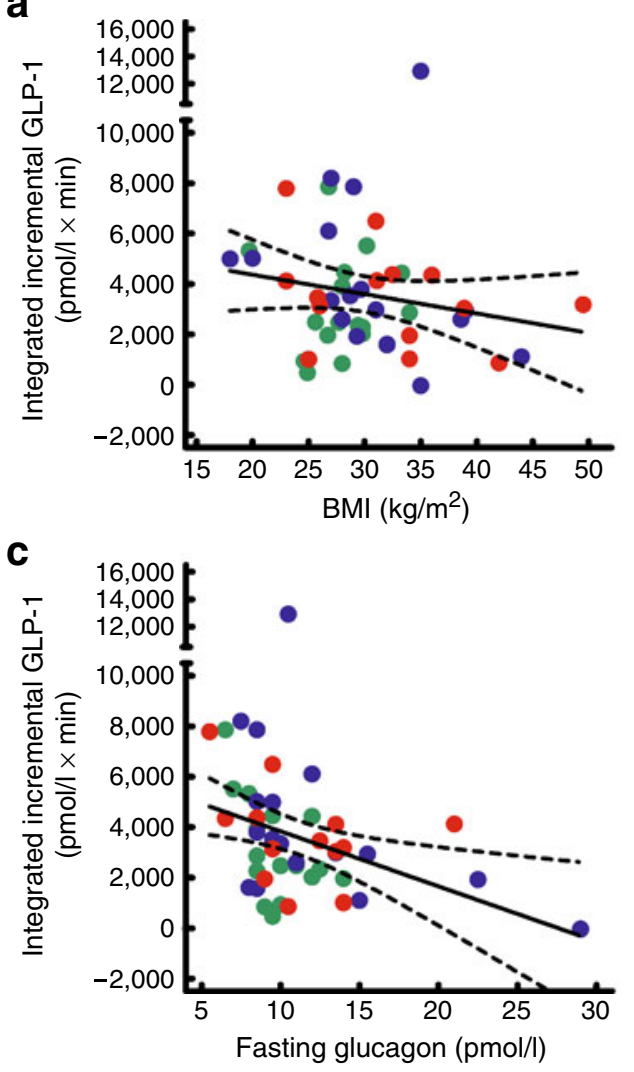

b

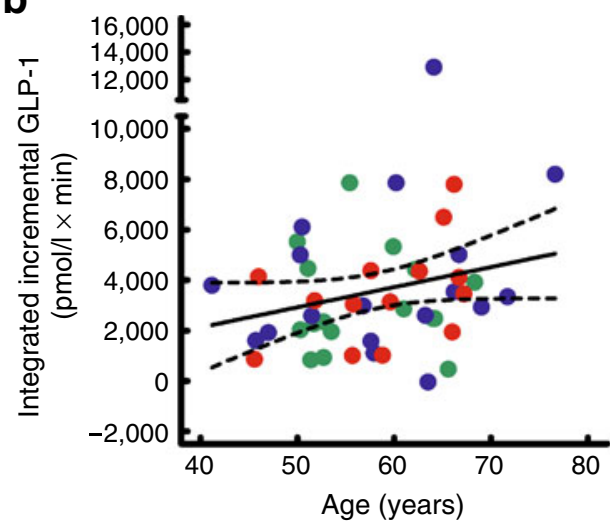

d

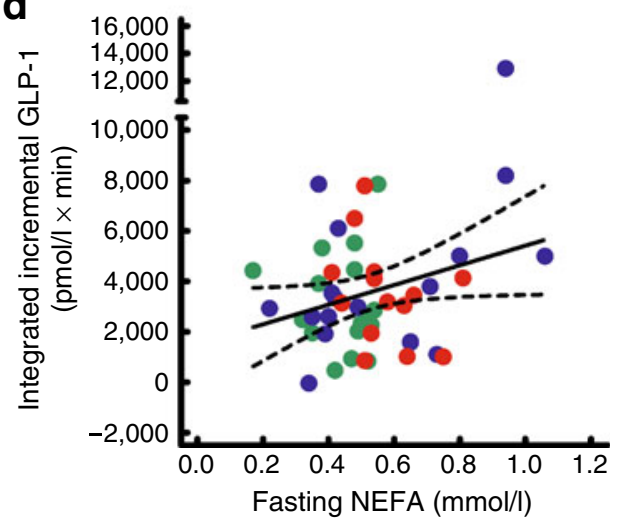

Factors that determine GLP-1 secretion give an indication why some studies found differences in GLP-1 secretory responses between type 2 diabetic patients and healthy controls, while others did not. These interdependences are illustrated in Table 2. Type 2 diabetic cohorts, especially if not perfectly matched to healthy participants, will tend to be older, more obese and exhibit hyperglucagonaemia as well as elevated fasting NEFA levels. Some of these factors predict lower GLP-1 responses (higher weight or BMI, and high glucagon concentrations), while others are determinants of enhanced GLP-1 secretion (older age, higher fasting NEFA concentrations). Therefore, the ability to predict 'normal' or impaired GLP-1 response in patients with type 2 diabetes will depend on the individual balance of these factors as well as the rate of gastric emptying. The same reasoning can be applied to reported studies. Thus Toft-Nielsen et al. [12] studied healthy and type 2 diabetic participants with similar fasting NEFA concentrations, but differences in glucagon levels. Otherwise (age, BMI) their participants were well matched, meaning that the overall balance was shifted towards reduced GLP-1 secretion. In our recent study, type 2 diabetic patients had high NEFA concentrations as well as hyperglucagonaemia, the influences of which may have balanced each other out, resulting in no net difference in GLP-1 secretory responses [25]. These analyses further strengthen the credibility of the associations described by multivariate regression analysis (Table 1). These associations, however, may only be valid in relatively well controlled patients with type 2 diabetes, in whom glucose-lowering treatment is administered as usual when the nutrient stimulation to trigger GLP-1 release is performed.

The mechanism driving glucagon-induced suppression of GLP-1 secretion has yet to be determined. Since GLP-1 is known to reduce glucagon $[38,55]$, a reverse association may apply. Alternatively, a third, unknown factor may influence GLP-1 secretion and glucagon, explaining this association. A link between glucagon and GLP-1 secretion has recently been confirmed [56]. Nevertheless, open questions remain. Can, for example, a direct effect be mediated by glucagon receptors on L-cells? Do motility effects contribute to a reduction of GLP-1 secretion, e.g. by slowing antro-duodenal transit of nutrients? Since approximately $40 \%$ of type 2 diabetic patients can be expected to have delayed gastric emptying, how does this affect GLP-1 secretion? Does autonomous neuropathy [12] play a role in this context? Is the influence of NEFA or similar ligands mediated by GPR 119, 120 or 40 ? Does this indicate that these receptors are located on the basolateral membrane, thereby being accessible and responsive to changes in circulating concentrations of NEFA? Are the NEFA that activate GPR 120 receptors the same ones that stimulate GLP-1 secretion, e.g. long-chain monounsaturated NEFA? 
Table 1 Multiple regression analysis of potential determinants of GLP-1 secretion after oral glucose loads or mixed meals

\begin{tabular}{|c|c|c|c|}
\hline Variable & $\beta \pm \mathrm{SE}$ & $B \pm \mathrm{SE}$ & $\begin{array}{l}t \text { test } \quad p \text { value } \\
(42 d f)\end{array}$ \\
\hline
\end{tabular}

GLP-1 after oral glucose ${ }^{\mathrm{a}}$

\begin{tabular}{|c|c|c|c|c|}
\hline Glucose tolerance $^{\mathrm{b}}$ & $0.20 \pm 0.26$ & $3.7 \pm 4.7$ & 0.78 & 0.44 \\
\hline Age (years) & $1.28 \pm 0.35$ & $82.4 \pm 22.1$ & 3.7 & 0.0006 \\
\hline BMI $\left(\mathrm{kg} / \mathrm{m}^{2}\right)$ & $-0.46 \pm 0.43$ & $-56.2 \pm 53.0$ & -1.06 & 0.30 \\
\hline Glucagon (pmol/1) & $-0.62 \pm 0.23$ & $-212 \pm 77$ & -2.76 & 0.0086 \\
\hline Insulin (pmol/l) & $0.08 \pm 0.17$ & $3.91 \pm 8.41$ & 0.47 & 0.64 \\
\hline NEFA (mmol/l) & $0.71 \pm 0.24$ & $4781 \pm 1606$ & 2.98 & 0.0048 \\
\hline \multicolumn{5}{|c|}{ GLP-1 after a mixed meal ${ }^{\mathrm{c}}$} \\
\hline Glucose tolerance $^{\mathrm{a}}$ & $0.06 \pm 0.27$ & $1.2 \pm 5.6$ & 0.21 & 0.83 \\
\hline Age (years) & $0.97 \pm 0.35$ & $71.5 \pm 26.0$ & 2.75 & 0.0088 \\
\hline BMI $\left(\mathrm{kg} / \mathrm{m}^{2}\right)$ & $-0.75 \pm 0.41$ & $-10.6 \pm 57.9$ & -0.18 & 0.86 \\
\hline Glucagon (pmol/1) & $-0.48 \pm 0.25$ & $-174.4 \pm 90.8$ & -1.92 & 0.062 \\
\hline Insulin (pmol/l) & $0.02 \pm 0.18$ & $1.07 \pm 9.95$ & 0.11 & 0.92 \\
\hline NEFA (mmol/l) & $0.49 \pm 0.23$ & $3766 \pm 1770$ & 2.13 & 0.039 \\
\hline
\end{tabular}

Integrated incremental GLP-1 responses were determined using methods for determining 'total' GLP-1 concentrations (including DPP-4 breakdown products)

$B$ and $\beta$ are the non-standardised and standardised regression coefficients, respectively, both displayed with their respective standard error (SE); data were re-analysed from Vollmer et al. [25]

Calculations: Statistica 5.0, StatSoft, Hamburg, Germany

${ }^{a}$ For the analysis of GLP-1 after oral glucose, the correlation coefficient squared $\left(R^{2}\right)$ was 0.784 , the corrected $R^{2}$ was 0.753 and the $F$ value with 6 and 42 degrees of freedom was 25.4 , for a $p$ value $<0.0001$

${ }^{\mathrm{b}}$ Glucose tolerance was entered as the continuous variable glucose concentration $120 \mathrm{~min}$ after $75 \mathrm{~g}$ oral glucose

${ }^{\mathrm{c}}$ For the analysis of GLP-1 after oral glucose, the correlation coefficient squared $\left(R^{2}\right)$ was 0.767 , the corrected $R^{2}$ was 0.734 and the $F$ value with 6 and 42 degrees of freedom was 23.1, for a $p$ value $<0.0001$

Can dietary manipulations be derived from such knowledge that would help sustain meal-related endogenous release of GLP-1, especially in patients treated with DPP-4 inhibitors?

\section{Augmenting L-cell GLP-1 secretion}

By doubling meal-related responses of intact, biologically active GLP-1, DPP-4 inhibitors exert profound effects on glycaemic control in patients with type 2 diabetes; indeed, any augmentation of GLP-1 responses would probably be welcome and could help control glycaemia in patients with type 2 diabetes.

Single dietary interventions have met with partial success. For example, protein preloads [57] or large quantities of single amino acids (glutamine) [58] have been used to elicit higher GLP-1 responses by enhancing GLP-1 secretion.

The fact that the majority of L-cells are located distally in the small intestine has prompted attempts to use $\alpha$-glucosidase inhibitors to prevent rapid digestion of starch and complex carbohydrates, thereby moving intestinal contents downwards and resulting in preferential digestion and absorption in the lower jejunum or ileum, where L-cells are most prevalent. In healthy participants receiving test meals composed of sucrose and acarbose or voglibose, this approach was highly effective, whereas in studies more realistically copying the ingestion of meals in patients with type 2 diabetes, the effects were rather small or completely negligible [59]. This may be different with second-generation $\alpha$-glucosidase inhibitors such as voglibose [60] and miglitol [61].

Recently, metformin was seen to lead to higher mealrelated increments in total and intact GLP-1, indicating a stimulation of GLP-1 secretion. Moreover, when metformin was combined with a DPP-4 inhibitor, concentrations of intact GLP-1 were increased beyond those observed with the DPP-4 inhibitor alone [51]. The effects of metformin are compatible with previous results from animal studies with metformin and other biguanide drugs [62]. The mechanism by which metformin augments GLP-1 responses is not entirely clear.

Certainly, there still is a lack of strategies to augment secretion of endogenous GLP-1 through dietary measures or with drugs specifically designed to stimulate L-cell secretion. We expect this to be an active area of research in the near future.

\section{Conclusions}

First, it is too early to conclude that advancing type 2 diabetes is characterised by a progressive loss of the potential to secrete GLP-1 as part of the process of disease progression. To draw such a conclusion, we need studies that longitudinally assess GLP-1 secretion in cohorts of prediabetic participants followed until diagnosis of type 2

Table 2 Typical characteristics in type 2 diabetic patients and their consequences for GLP-1 secretion based on univariate and multivariate regression analysis of factors determining GLP-1 responses assessed from previously reported data ${ }^{a}$

Variable Typical consequences

In type 2 diabetes For GLP-1 secretion

\begin{tabular}{lll}
\hline Age & $\uparrow$ & $\uparrow$ \\
Body weight $^{\mathrm{b}}$ & $\uparrow$ & $\downarrow$ \\
Glucagon & & $\downarrow$ \\
NEFA & $\uparrow$ & $\uparrow$ \\
Overall individual balance & $\approx$ or $\downarrow$ or $\uparrow$ &
\end{tabular}

${ }^{\text {a }}$ Vollmer et al. [25]

${ }^{\mathrm{b}}$ Influence of body weight was significant upon univariate (Fig. 3), but not multiple regression analysis (Table 1) 
diabetes and through progression over the following years. Current data allow hypotheses, but not predictions of the results of such a study.

Second, small differences in GLP-1 concentrations within physiological limits are not sufficient to affect insulin secretion. Physiological replacement of GLP-1 by exogenous administration had little effect, but this may underestimate the role of endogenous GLP-1 for insulin secretion, because intravenous administration bypasses important hepato-portal sensors for GLP-1 [63]. Certainly, differences during the second and third hour after meal stimulation as reported by Toft-Nielsen et al. [12] do not help to explain any of the important differences in earlyphase insulin secretion that are typical of type 2 diabetes (and are found in the first 30 to $60 \mathrm{~min}$ after meal ingestion begins). The reduced incretin effect in type 2 diabetic patients is much more closely related to the losses in insulinotropic activity of GIP, which are typical of this condition, and less so to those related to GLP-1 [64].

Third, and for the same reason(s), any observed deficit in GLP-1 responses after meals does not simply call for a 'true' replacement therapy with incretin-based glucoselowering medications. Incretin mimetics provide a pharmacological stimulus to insulin secretion and elicit other GLP1-receptor-mediated activity as drugs, but are typically introduced at much higher concentrations compared with physiological levels of GLP-1 $[65,66]$.

Finally, and as a consequence of the above, DPP-4 inhibitors can exert their clinical effects even in advanced stages of type 2 diabetes. This condition is not in itself characterised by reduced meal-induced GLP-1 concentrations that are too low to be effective, as supported by recent studies [67].

In conclusion, while reduced GLP-1 levels have been described individually in some participants as well as in groups with type 2 diabetes mellitus, this does not seem to be a universal characteristic that is representative of all patients.

Acknowledgements We thank K. Vollmer, Ruhr-University Bochum, Germany, for providing original data from her study (Vollmer et al. [25]) for further analysis.

Duality of interest The authors declare that there is no duality of interest associated with this manuscript.

\section{References}

1. Creutzfeldt W, Nauck M (1992) Gut hormones and diabetes mellitus. Diabetes/Metab Rev 8:149-177

2. Holst JJ, Ørskov C (2001) Incretin hormones - an update. Scand J Clin Lab Invest 234(suppl):75-85

3. Drucker DJ, Nauck MA (2006) The incretin system: glucagon-like peptide-1 receptor agonists and dipeptidyl peptidase-4 inhibitors in type 2 diabetes. Lancet 368:1696-1705
4. Meier JJ, Nauck MA (2004) The potential role of glucagon-like peptide 1 in diabetes. Curr Opin Investig Drugs 5:402-410

5. Nauck MA, Meier JJ, Creutzfeldt W (2003) Incretins and their analogues as new antidiabetic agents. Drug News Perspect $16: 413-422$

6. Nauck MA, Meier JJ (2005) Glucagon-like peptide 1 (GLP-1) and its derivatives in the treatment of diabetes. Regul Pept 124 (suppl): 135-148

7. Deacon CF, Holst JJ (2006) Dipeptidyl peptidase IV inhibitors: a promising new therapeutic approach for the management of type 2 diabetes. Int J Biochem Cell Biol 38:831-844

8. Åhren B (2007) DPP-4 inhibitors. Best Pract Res Clin Endocrinol Metab 21:517-533

9. Holst JJ, Deacon CF (2005) Glucagon-like peptide-1 mediates the therapeutic actions of DPP-IV inhibitors. Diabetologia 48:612 615

10. Toft-Nielsen MB, Madsbad S, Holst JJ (2001) Determinants of the effectiveness of glucagon-like peptide- 1 in type 2 diabetes. J Clin Endocrinol Metab 86:3853-3860

11. Lugari R, Dei Cas A, Ugolotti D et al (2002) Evidence for early impairment of glucagon-like peptide 1-induced insulin secretion in human type 2 (non insulin-dependent) diabetes. Horm Metab Res $34: 150-154$

12. Toft-Nielsen MB, Damholt MB, Madsbad S et al (2001) Determinants of the impaired secretion of glucagon-like peptide1 in type 2 diabetic patients. J Clin Endocrinol Metab 86:37173723

13. Nauck M, Stöckmann F, Ebert R, Creutzfeldt W (1986) Reduced incretin effect in type 2 (non-insulin-dependent) diabetes. Diabetologia 29:46-54

14. Knop FK, Vilsbøll T, Højberg PV et al (2007) Reduced incretin effect in type 2 diabetes: cause or consequence of the diabetic state? Diabetes 56:1951-1959

15. Eissele R, Göke R, Willemer S et al (1992) Glucagon-like peptide- 1 cells in the gastrointestinal tract and pancreas of rat, pig and man. Eur J Clin Invest 22:283-291

16. Kreymann B, Williams G, Ghatei MA, Bloom SR (1987) Glucagon-like peptide-1 [7-36]: a physiological incretin in man. Lancet 2:1300-1304

17. Ørskov C, Knuhtsen S, Baldissera FG, Poulsen SS, Nielsen OV, Holst JJ (1986) Glucagon-like peptides GLP-1 and GLP-2, predicted products of the glucagon gene, are secreted separately from pig small intestine but not pancreas. Endocrinology 119:1467-1475

18. Ørskov C, Jeppesen J, Madsbad S, Holst JJ (1991) Proglucagon products in plasma of noninsulin-dependent diabetics and nondiabetic controls in the fasting state and after oral glucose and intravenous arginine. J Clin Invest 87:415-423

19. D'Alessio D, Thirlby R, Laschansky E, Zebroski H, Ensinck J (1993) Response of tGLP-1 to nutrients in humans. Digestion 54:377-379

20. Nauck MA, El-Ouaghlidi A, Gabrys B et al (2004) Secretion of incretin hormones (GIP and GLP-1) and incretin effect after oral glucose in first-degree relatives of patients with type 2 diabetes. Regul Pept 122:209-217

21. Ørskov C, Rabenhøj L, Wettergren A, Kofod H, Holst JJ (1994) Tissue and plasma concentrations of amidated and glycineextended glucagon-like peptide 1 in humans. Diabetes 43:535539

22. Åhren B, Holst JJ (2001) The cephalic insulin response to meal ingestion in humans is dependent on both cholinergic and noncholinergic mechanisms and is important for postprandial glycemia. Diabetes 50:1030-1038

23. Rask E, Olsson T, Soderberg S et al (2001) Impaired incretin response after a mixed meal is associated with insulin resistance in nondiabetic men. Diabetes Care 24:1640-1645 
24. Vilsbøll T, Krarup T, Deacon CF, Madsbad S, Holst JJ (2001) Reduced postprandial concentrations of intact biologically active glucagon-like peptide 1 in type 2 diabetic patients. Diabetes 50:609-613

25. Vollmer K, Holst JJ, Baller B et al (2008) Predictors of incretin concentrations in subjects with normal, impaired, and diabetic glucose tolerance. Diabetes 57:678-687

26. Reimann F (2006) GLP-1. Diabetes 5(suppl 1):S 78-85

27. Jang HJ, Kokrashvili Z, Theodorakis MJ et al (2007) Gut-expressed gustducin and taste receptors regulate secretion of glucagon-like peptide-1. Proc Natl Acad Sci USA 104:15069-15074

28. Lauffer LM, Iakoubov R, Brubaker PL (2009) GPR119 is essential for oleoylethanolamide-induced glucagon-like peptide-1 secretion from the intestinal enteroendocrine L-cell. Diabetes 58:1058-1066

29. Hirasawa A, Tsumaya K, Awaji T et al (2005) Free fatty acids regulate gut incretin glucagon-like peptide-1 secretion through GPR120. Nat Med 11:90-94

30. Zhao X, Cui YM, Zhou Y et al (2008) Exenatide pharmacokinetics in healthy Chinese subjects. Int J Clin Pharmacol Ther 46:459-465

31. Gray GM (1970) Carbohydrate digestion and absorption. Gastroenterol 58:96-107

32. Herrmann-Rinke C, Vöge A, Hess M, Göke B (1995) Regulation of glucagon-like peptide-1 secretion from rat ileum by neurotransmitters and peptides. J Endocrinol 147:25-31

33. Brubaker PL (1991) Regulation of intestinal proglucagon-derived peptide secretion by intestinal regulatory peptides. Endocrinol 128:3175-3182

34. Rocca AS, Brubaker PL (1999) Role of the vagus nerve in mediating proximal nutrient-induced glucagon-like peptide-1 secretion. Endocrinology 140:1687-1694

35. Anini Y, Brubaker PL (2003) Muscarinic receptors control glucagon-like peptide 1 secretion by human endocrine L cells. Endocrinology 144:3244-3250

36. Roberge JN, Brubaker PL (1993) Regulation of intestinal proglucagon-derived peptide secretion by glucose-dependent insulinotropic peptide in a novel enteroendocrine loop. Endocrinology 133:233-240

37. Roberge JN, Gronau KA, Brubaker PL (1996) Gastrin-releasing peptide is a novel mediator of proximal nutrient-induced proglucagonderived peptide secretion from the distal gut. Endocrinology 137: 2383-2388

38. Nauck MA, Heimesaat MM, Ørskov C, Holst JJ, Ebert R, Creutzfeldt W (1993) Preserved incretin activity of glucagonlike peptide 1 [7-36 amide] but not of synthetic human gastric inhibitory polypeptide in patients with type-2 diabetes mellitus. J Clin Invest 91:301-307

39. Fieseler P, Bridenbaugh S, Nustede R et al (1995) Physiological augmentation of amino acid-induced insulin secretion by GIP and GLP-I but not by CCK-8. Am J Physiol (Endocrinol Metab) 268: E 949-955

40. Balks HJ, Holst JJ, von zur Mühlen A, Brabant G (1997) Rapid oscillations in plasma glucagon-like peptide-1 (GLP-1) in humans: cholinergic control of GLP-1 secretion via muscarinic receptors. J Clin Endocrinol Metab 82:786-790

41. Beglinger S, Drewe J, Schirra J, Göke B, D’Amato M, Beglinger C (2010) Role of fat hydrolysis in regulating glucagon-like peptide-1 secretion. J Clin Endocrinol Metab 95:879-886

42. Nauck MA, Siemsglüß J, Ørskov C, Holst JJ (1996) Release of glucagon-like peptide 1 (GLP-1 [7-36 amide]), gastric inhibitory polypeptide (GIP) and insulin in response to oral glucose after upper and lower intestinal resections. Z Gastroenterol 34:159-166

43. Hansen L, Lampert S, Mineo H, Holst JJ (2004) Neural regulation of glucagon-like peptide-1 secretion in pigs. Am J Physiol (Endocrinol Metab) 287:E 939-947

44. Theodorakis MJ, Carlson O, Michopoulos S et al (2006) Human duodenal enteroendocrine cells: source of both incretin peptides,
GLP-1 and GIP. Am J Physiol (Endocrinol Metab) 290:E 550559

45. Mortensen K, Petersen LL, Orskov C (2000) Colocalization of GLP-1 and GIP in human and porcine intestine. Ann N Y Acad Sci 921:469-472

46. Nauck MA, Holst JJ, Willms B, Schmiegel W (1997) Glucagonlike peptide 1 (GLP-1) as a new therapeutic approach for type 2diabetes. Exp Clin Endocrinol Diabetes 105:187-195

47. Schirra J, Katschinski M, Weidmann C et al (1996) Gastric emptying and release of incretin hormones after glucose ingestion in humans. J Clin Invest 97:92-103

48. Miholic J, Ørskov C, Holst JJ, Kotzerke J, Meyer HJ (1991) Emptying of the gastric substitute, glucagon-like peptide-1 (GLP-1), and reactive hypoglycemia after total gastrectomy. Dig Dis Sci 36:1361-1370

49. Fukase N, Takahashi H, Manaka H et al (1992) Differences in glucagon-like peptide-1 and GIP responses following sucrose ingestion. Diabetes Res Clin Pract 15:187-195

50. Patzelt C, Schiltz E (1984) Conversion of proglucagon in pancreatic alpha cells: the major endproducts are glucagon and a single peptide, the major proglucagon fragment, that contains two glucagon-like sequences. Proc Natl Acad Sci USA 81:5007-5011

51. Migoya E, Miller J, Luo W-L et al (2010) Sitagliptin and metformin increase active GLP-1 by complementary mechanisms in treatmentnaïve patients with type 2 diabetes. Diabetes 59(suppl 1):A 156

52. Ranganath LR, Beety LM, Morgan LM, Wright JW, Howland R, Marks V (1996) Attenuated GLP-1 secretion in obesity: cause or consequence? Gut 38:916-919

53. Hansen L, Hartmann B, Mineo H, Holst JJ (2004) Glucagon-like peptide-1 secretion is influenced by perfusate glucose concentration and by a feedback mechanism involving somatostatin in isolated perfused porcine ileum. Regul Pept 118:11-18

54. Muscelli E, Mari A, Casolaro A et al (2008) Separate impact of obesity and glucose tolerance on the incretin effect in normal subjects and type 2 diabetic patients. Diabetes 57:1340-1348

55. Nauck MA, Kleine N, Ørskov C, Holst JJ, Willms B, Creutzfeldt W (1993) Normalization of fasting hyperglycaemia by exogenous glucagon-like peptide 1 (7-36 amide) in type 2 (non-insulindependent) diabetic patients. Diabetologia 36:741-744

56. Meier JJ, Ritter PR, Jacob A et al (2010) Impact of exogenous hyperglucagonemia on postprandial concentrations of gastric inhibitory polypeptide and glucagon-like peptide-1 in humans. J Clin Endocrinol Metab 95:4061-4065

57. Ma J, Stevens JE, Cukier K et al (2009) Effects of a protein preload on gastric emptying, glycemia, and gut hormones after a carbohydrate meal in diet-controlled type 2 diabetes. Diabetes Care 32:1600-1602

58. Greenfield JR, Farooqi IS, Keogh JM et al (2009) Oral glutamine increases circulating glucagon-like peptide 1, glucagon, and insulin concentrations in lean, obese, and type 2 diabetic subjects. Am J Clin Nutr 89:106-113

59. Seifarth C, Bergmann J, Holst JJ, Ritzel R, Schmiegel W, Nauck MA (1998) Prolonged and enhanced secretion of glucagon-like peptide 1 (7-36 amide) after oral sucrose due to alpha-glucosidase inhibition (acarbose) in type 2 diabetic patients. Diabet Med 15:485491

60. Göke B, Fuder H, Wieckhorst G et al (1995) Voglibose (AO-128) is an efficient alpha-glucosidase inhibitor and mobilizes the endogenous GLP-1 reserve. Digestion 56:493-501

61. Lee A, Patrick P, Wishart J, Horowitz M, Morley JE (2002) The effects of miglitol on glucagon-like peptide-1 secretion and appetite sensations in obese type 2 diabetics. Diabetes Obes Metab 4:329-335

62. Yasuda N, Inoue T, Nagakura T et al (2002) Enhanced secretion of glucagon-like peptide 1 by biguanide compounds. Biochem Biophys Res Commun 298:779-784 
63. Burcelin R, Da Costa A, Drucker D, Thorens B (2001) Glucose competence of the hepatoportal vein sensor requires the presence of an activated glucagon-like peptide-1 receptor. Diabetes 50:1720-1728

64. Kjems LL, Holst JJ, Vølund A, Madsbad S (2003) The influence of GLP-1 on glucose-stimulated insulin secretion: effects on betacell sensitivity in type 2 and nondiabetic subjects. Diabetes $52: 380-386$

65. Kolterman OG, Kim DD, Shen L et al (2005) Pharmacokinetics, pharmacodynamics, and safety of exenatide in patients with type 2 diabetes mellitus. Am Health Syst Pharm 62:173181

66. Elbrønd B, Jakobsen G, Larsen S et al (2002) Pharmacokinetics, pharmacodynamics, safety, and tolerability of a single-dose of NN2211, a long-acting glucagon-like peptide 1 derivative, in healthy male subjects. Diabetes Care 25:1398-1404

67. Fonseca V, Baron M, Shao Q, Dejager S (2008) Sustained efficacy and reduced hypoglycemia during one year of treatment with vildagliptin added to insulin in patients with type 2 diabetes mellitus. Horm Metab Res 40:427-430

68. Vilsbøll T, Krarup T, Sonne J et al (2003) Incretin secretion in relation to meal size and body weight in healthy subjects and people with type 1 and type 2 diabetes mellitus. J Clin Endocrinol Metab 88:2706-2713

69. Ryskjaer J, Deacon CF, Carr RD et al (2006) Plasma dipeptidyl peptidase-IV activity in patients with type- 2 diabetes mellitus correlates positively with $\mathrm{HbA}_{1 \mathrm{c}}$ levels, but is not acutely affected by food intake. Eur J Endocrinol 155:485-493

70. Salinari S, Bertuzzi A, Asnaghi S, Guidone C, Manco M, Mingrone G (2009) First-phase insulin secretion restoration and differential response to glucose load depending on the route of administration in type 2 diabetic subjects after bariatric surgery. Diabetes Care 32:375-380

71. Fukase N, Igarashi M, Takahashi $\mathrm{H}$ et al (1993) Hypersecretion of truncated glucagon-like peptide-1 and gastric inhibitory polypeptide in obese patients. Diabet Med 10:44-49 